\title{
ACHIEVING A BALANCE BETWEEN EXPLORATION AND EXPLOITATION IN SERVICE FIRMS: A LONGITUDINAL STUDY
}

\author{
ANNELIES GEERTS \\ Vlerick Leuven Gent Management School \\ Reep 1, 9000 Gent \\ Belgium \\ FLOORTJE BLINDENBACH-DRIESSEN \\ Vlerick Leuven Gent Management School, Belgium \\ PAUL GEMMEL \\ Ghent University, Belgium \\ Vlerick Leuven Gent Management School, Belgium
}

\begin{abstract}
Whereas ambidexterity is frequently associated with simultaneous exploration and exploitation, others concluded that exploration and exploitation can also be achieved by a punctuated equilibrium. Drawing on longitudinal data of 532 firms, we show that ambidexterity and punctuated equilibrium have a positive effect on firm performance in manufacturing and service firms.
\end{abstract}

\section{INTRODUCTION}

Since Schumpeter's theory of economic development (Schumpeter, 1934), innovation has taken shape as one of the most powerful explanatory elements for long-term growth (Drejer, 2004). From the ambidexterity literature it is known that not innovation per se, but the balance between exploratory and exploitative types of innovation enables firms to be effective in the short run, to survive in the long run and to achieve superior performance (Benner \& Tushman, 2003; He \& Wong, 2004; Sheremata, 2000; Tushman \& O'Reilly, 1996). Balancing exploration and exploitation, is far from easy as both often draw from the same resources, yet ask for a very different strategic mindset (Gupta, Smith, \& Shalley, 2006; March, 1991; Tushman \& O'Reilly, 1996). The concept of ambidexterity has increasingly been subject of research in leading management journals during the past few years (Raisch, Birkinshaw, Probst, \& Tushman, 2009). In general, previous studies of ambidexterity have focused on the concept from a technological point of view and examined how it contributes to firm performance (Lubatkin, Simsek, Yan, \& Veiga, 2006; Rothaermel \& Alexandre, 2009). We know little, however, about the link between different economic industries and ambidexterity.

The purpose of this paper is to investigate whether for service firms, the question of ambidexterity is as important as it is for manufacturing firms, and whether there are differences in the way a balance between exploration and exploitation is achieved between service and manufacturing firms.

Drawing on longitudinal, quantitative survey data of 532 firms, we first examine which mechanism manufacturing and service firms use to achieve a balance between exploration and exploitation. Second, we investigate the effect of ambidexterity and punctuated equilibrium on firm performance growth. Third, we explore whether ambidexterity has a positive effect on 
performance growth in manufacturing firms, and if punctuated equilibrium has a similar effect in service firms. We use data from the Belgian Community Innovation Survey (CIS) ${ }^{1}$ for a period of five years. In addition, a firm performance database, Bel-First, is used to link the practiced innovation mechanism of our sample to performance growth. As the difference in financial performance did not explain the difference in the use of various methods to achieve a balance between exploration and exploitation, we performed multiple case study research to understand in-depth the drivers why service firms prefer the punctuated equilibrium over the simultaneous ambidexterity model.

\section{THEORETICAL BACKGROUND AND HYPOTHESES}

The concept of ambidexterity has been used in various works, ranging from technological change to organization design (Raisch \& Birkinshaw, 2008). Although various definitions exist, there is a broad agreement that organizational ambidexterity relates to the simultaneous pursuit of exploratory and exploitative activities (Cao, Gedajlovic, \& Zhang, 2009; Gibson \& Birkinshaw, 2004; Tushman \& O'Reilly, 1996). Following Jansen, Van den Bosch, and Volberda (2005), we define ambidexterity as the ability to pursue exploratory and exploitative innovations simultaneously.

In the light of the growing interest on ambidexterity, researchers began to question whether simultaneously exploring and exploiting is the only way to achieve a balance between both activities. Scholars identified punctuated equilibrium as an alternative way to achieve a balance between exploration and exploitation (Burgelman, 2002; Gupta et al., 2006; Siggelkow \& Levinthal, 2003; Tushman \& Romanelli, 1985). Punctuated equilibrium is defined as cycling through periods of exploration and exploitation (Gupta et al., 2006). Related to this view, the concept of 'sequential ambidexterity', time-spaced sequence of exploration and exploitation, is developed (Puranam, Singh, \& Zollo, 2006; Venkatraman et al., 2007).

Tushman and O'Reilly (1996) suggest that firms able of simultaneously pursuing exploration and exploitation are more likely to achieve higher performance than firms focusing on one at the expense of the other. Firms who mainly engage in exploration will experience difficulties in estimating their returns a priori. It may take long time before performance benefits actually arise, if at all (Volberda \& Lewin, 2003). On the opposite, firms who principally concentrate on exploitation usually achieve returns that are proximate and predictable but not necessarily sustainable (Levinthal \& March, 1993).

A firm's ability to be successful in the long run is thus linked to the ability of being ambidextrous (Gibson \& Birkinshaw, 2004; He \& Wong, 2004; Lubatkin et al., 2006). Contrary to these findings, Venkatraman, Lee and Iyer (2007) did not found empirical evidence for the ambidexterity hypothesis. Instead, they found that temporal cycling through periods of exploration and exploitation has a positive effect on firm performance. This supports punctuated equilibrium as a way for achieving a balance between exploration and exploitation. In general, empirical evidence of the relationship between ambidexterity or punctuated equilibrium and performance remains limited and mixed. Examining the effect of punctuated equilibrium is important, since not all firms are able or choose to pursue simultaneously exploration and exploitation (Siggelkow \& Levinthal, 2003). Except for the study of Venkatraman et al. (2007), no direct empirical test of punctuated equilibrium's impact on firm performance exists in the literature. Based on the previously discussed literature we hypothesize that firms who are ambidextrous as well as firms who pursue the punctuated equilibrium mechanism will experience a positive effect on performance growth. 
Hypothesis 1: Ambidexterity has a positive effect on firm performance growth.

Hypothesis 2: Punctuated equilibrium has a positive effect on firm performance growth.

Sundbo and Gallouj (1999) define innovations in the service sector as more incremental innovations, based on small adjustments of procedures. However, can service firms show longterm growth based on exploitation only? Van Ark, Broesma and Hertog (2003) define innovations in service firms as multidimensional processes, less technological compared with manufacturing but with more emphasis on the organizational aspect. The latter could imply that service firms do not need to continuously invest in an exploratory type of innovation capabilities to keep up to date with the most recent technologies. This would enable service firms to explore on a more ad-hoc and opportunity bases, as suggested by the advocates of the punctuated equilibrium model (Gersick, 1991; Tushman \& Romanelli, 1985).

We hypothesize that there is a significant difference in innovation behavior between service firms and manufacturing firms, whereby manufacturing firms are more likely to use the ambidexterity model and service firms the punctuated-equilibrium model.

Hypothesis 3: Manufacturing firms balance between exploration and exploitation simultaneously.

Hypothesis 4: Service firms alternate between exploration and exploitation over time.

Besides a difference in behavior, we also expect that for both types of firms one behavior leads to superior performance than the other. Thus, that in manufacturing firms the ambidexterity model leads to superior long-term growth over the punctuated equilibrium model and that for service firms the punctuated equilibrium model leads to superior growth over the ambidexterity model.

Hypothesis 5: Ambidexterity has a more positive effect on performance growth in manufacturing firms than in service firms.

Hypothesis 6: Punctuated equilibrium has a more positive effect on performance growth in service firms than in manufacturing firms.

\section{RESULTS}

The conceptualization, means, standard deviations and correlations for the independent, control and dependent variables in this study can be obtained from the authors, as well as detailed information on the cases.

Insert Table 1 about here 
Insert Table 2 about here

A cross-tabulation and t-statistic, see Table 1, show us the results for testing our hypothesis that manufacturing firms rather pursue ambidexterity while service firms prefer the punctuated equilibrium model. Innovation behavior is found to be different between manufacturing firms and service firms. As illustrated in Table 1, a t-test shows that service firms tend towards punctuated equilibrium, exploitation and no innovation. This is also suggested by the frequency percentages in the cross-tabulation and thus supports our hypothesis that innovative service firms rather pursue a punctuated equilibrium. In addition, we find support for our hypothesis that innovative manufacturing firms more often choose for ambidexterity as a way to achieve a balance between exploration and exploitation.

Table 2 shows the regression results for firm performance growth. We started by estimating a model that relates the control variables to firm performance growth (model 1). In examining the effect of control variables, we find that the effect of firm size, measured by the number of employees, was negative and significant $(p<.001)$, suggesting that performance growth decreases as the total number of employees increases. A positive and significant effect $(p$ $<.001)$ is found for firm size, in terms of turnover. Performance growth increases as turnover increases. Furthermore, a significant effect $(p<.001)$ is found for R\&D expenses, indicating that performance growth increases as the R\&D expenses of a firm increase. Hypotheses 1 and 2 state that ambidexterity and punctuated equilibrium both have a positive effect on firm performance growth. In our next model (model 2), we test these hypotheses by adding the independent variables to relate them to firm performance growth. Dummy variables were included since our independent variable innovation behavior was categorical. We find a positive significant effect on performance growth for both ambidexterity $(p<.05)$ and punctuated equilibrium $(p<.05)$, with reference to the category non innovative firms. These findings support our hypotheses 1 and 2 by suggesting that firms pursuing ambidexterity or punctuated equilibrium will experience an increase in firm performance growth. No significant effects were found for firms focusing solely on exploration or exploitation. Model 3 includes interactions between the independent variables and tests hypotheses 5 and 6.We find no support for hypothesis 5 that ambidexterity has a more positive effect on performance growth in manufacturing firms. Also, no evidence is found for hypothesis 6 that punctuated equilibrium has a more positive effect on performance growth in service firms.

Because the manufacturing - service sector aggregation may not capture the technological and knowledge dynamism of different markets, we did additional analysis with an aggregation according to the technological and knowledge intensity of manufacturing and service firms. These findings confirm a difference in innovation behavior between high-technology manufacturing firms and knowledge intensive service firms. A difference in innovation behavior is also found between low-technology manufacturing firms and less knowledge intensive service firms. Both types of manufacturing firms tend more towards ambidexterity and exploration, than to the two types of service firms. However, we cannot find that the preferred behavior is linked to more growth for any of these sub-categories either. 
That a difference in performance growth does not explain the difference in the use of various methods to achieve a balance between exploration and exploitation, could imply that other variables play a role why firms prefer one method above the other. Therefore, we performed multiple case study research to understand in-depth the drivers why service firms prefer the punctuated equilibrium over the simultaneous ambidexterity model.

There appear to be several drivers that determine whether ambidexterity or punctuated equilibrium is favored as a way to achieve a balance between exploration and exploitation. First, it seems that a highly competitive environment tends service firms towards ambidexterity. When a high environmental pressure is experienced, firms could have no other choice than simultaneously exploring and exploiting in order to survive and to create competitive advantage. Second, the values carried out by top management, together with the more general strategic orientation, enable ambidexterity or punctuated equilibrium. Leadership plays a crucial role in the innovation behavior of firms (Brown \& Eisenhardt, 1997; Smith \& Tushman, 2005), also in the firms we studied. During the interviews, it became clear that employees would not invest time in exploration or exploitation activities if management would not frequently point out the importance of innovation and the balancing exploration-exploitation act. Third, available resources are critical for firms in choosing whether to simultaneously explore and exploit, or alternate both activities. For example, one firm considered a lack of human resources as a barrier for ambidexterity. Firm size may facilitate ambidexterity, but the internal organization of the firms seems to matter more. If management enables the employees to both explore and exploit at the same time, ambidexterity can be easily achieved in a small or medium sized company.

\section{DISCUSSION AND CONCLUSIONS}

March's (1991) proposition on the importance of a balance between exploration and exploitation is well acknowledged (Gibson \& Birkinshaw, 2004; He \& Wong, 2004; Lubatkin et al., 2006; Venkatraman et al., 2007). Whereas ambidexterity is frequently seen as the solution to balance exploration and exploitation (Benner \& Tushman, 2003; He \& Wong, 2004), other scholars concluded that both can also be alternated through a punctuated equilibrium (Burgelman, 2002; Gersick, 1991). This study provides an empirical test of ambidexterity and punctuated equilibrium in a longitudinal way and compares the manufacturing sector with the service sector. In addition, multiple case study research is used to gain in-depth knowledge on the drivers for ambidexterity and punctuated equilibrium in service firms.

We find that ambidexterity and the punctuated equilibrium have a positive effect on firm performance growth. These findings suggest that there is more than one mechanism to achieve a balance between exploration and exploitation, resulting in a firm performance increase. Our empirical findings show that manufacturing firms rather pursue ambidexterity, while service firms more often choose for punctuated equilibrium. However, growth does not explain why the punctuated equilibrium mechanism is preferred by the service sector. We performed multiple case study research to understand in-depth the drivers why service firms prefer the punctuated equilibrium over the simultaneous ambidexterity model.

Our case study analysis suggests that service firms can wait with investing in radically new capabilities and jump in later, when an opportunity or certain need occurs. Corresponding to descriptions of innovation in service firms (Sundbo \& Gallouj, 1999; Van Ark et al., 2003), we found evidence that service firms seem to prefer mainly exploitative innovation activities, whereby creating value for the customers and improving efficiency in the service delivery is most important. Exploration, resulting in radical innovations, is often ad hoc based. Whether a service 
firm chooses for punctuated equilibrium or ambidexterity seems to strongly depend on the environmental pressures experienced, together with the leadership and available resources. High environmental pressures tend to favor ambidexterity. In addition, managers need to stimulate exploration and exploitation and create the opportunity to pursue both activities.

\section{ENDNOTES}

1.We would like to thank the Center for R\&D Monitoring for providing us with the CIS databases.

\section{REFERENCES}

(References can be obtained from the authors)

\section{TABLE 1 Differences in Frequency Based on Firm Type}

\begin{tabular}{lrrr}
\hline & Manufacturing & Service & t-statistic \\
\hline & & & $-3.34 * *$ \\
No innovation & $27.2 \%$ & $40.4 \%$ & \\
Exploitation & $14.0 \%$ & $13.1 \%$ & \\
Punctuated equilibrium & $24.4 \%$ & $24.0 \%$ & \\
Exploration & $4.9 \%$ & $2.7 \%$ & \\
Ambidexterity & $29.5 \%$ & $19.7 \%$ & \\
$* * p<.01$ & & &
\end{tabular}

TABLE 2 Results of Regression Analysis for Firm Performance Growth

\begin{tabular}{lccc}
\hline Variables & Model 1 & Model 2 & Model 3 \\
\hline Firm size in employees & $-0.43^{* *}$ & $-0.43^{* *}$ & $-0.43^{* *}$ \\
Firm size in turnover & $0.30^{* *}$ & $0.30^{* *}$ & $0.30^{* *}$ \\
R\&D expenses & $0.14^{* *}$ & $0.08^{*}$ & $0.08^{*}$ \\
Firm Type & & -0.01 & -0.01 \\
Exploitation & & -0.01 & -0.01 \\
Exploration & & -0.00 & -0.00 \\
Punctuated equilibrium & & $0.08^{*}$ & $0.08^{*}$ \\
Ambidexterity & & $0.11^{*}$ & $0.12^{*}$ \\
Firm type $\times$ punctuated equilibrium & & & 0.01 \\
Firm type $\times$ ambidexterity & & & 0.00 \\
& & & \\
$\mathrm{R}^{2}$ & $.09 * *$ & $.10^{* *}$ & $.10^{* *}$ \\
Adjusted $\mathrm{R} 2$ & $.08^{* *}$ & $.08^{* *}$ & $.08^{* *}$ \\
\hline
\end{tabular}

$* p<.05 ; * * p<.01$ 